\title{
Seismological monitoring of the February 2007 effusive eruption of the Stromboli volcano
}

\author{
Marcello Martini ( $\left.{ }^{(}\right)$, Flora Giudicepietro $\left({ }^{1}\right)$, Luca D'Auria $\left({ }^{1}\right)$, Antonietta M. Esposito $\left({ }^{1}\right)$, \\ Teresa Caputo $\left({ }^{1}\right)$, Raffaele Curciotti $\left({ }^{1}\right)$, Walter De Cesare $\left({ }^{1}\right)$, Massimo Orazi $\left({ }^{1}\right)$, Giovanni Scarpato $\left({ }^{1}\right)$, \\ Antonio Caputo $\left({ }^{1}\right)$, Rosario Peluso $\left({ }^{1}\right)$, Patrizia Ricciolino $\left({ }^{1}\right)$, Alan Linde $\left(^{(2)}\right.$ and Selwyn Sacks $\left({ }^{2}\right)$ \\ (') Istituto Nazionale di Geofisica e Vulcanologia, Osservatorio Vesuviano, Sezione di Napoli, Italy \\ ${ }^{2}{ }^{2}$ Carnegie Institution of Washington, 530 P Street NW, Washington, U.S.A.
}

\begin{abstract}
On February 27, 2007, the Stromboli volcano, which has usually been characterized by moderate explosive activity, started an effusive eruption with a small lava flow down the NW flank. The permanent broadband network installed on the island allowed the revealing of anomalies in the seismicity before the effusive eruption and for the phenomena to be followed over time, thus obtaining meaningful information about the eruption dynamics. During the effusive phase, a major explosion occurred on March 15, 2007. On that occasion, two strainmeters deployed on the volcano in the previous year recorded a strain increment before the blast. After this explosion, which further destabilized the upper part of the edifice, swarms of Long-Period (LP) and hybrid events were recorded. The characteristics and locations of these events suggest that they were associated with the fracturing processes that affected the summit area of the cone. During the effusive phase, changes in the Very Long Period (VLP) event location were recorded. This type of events accompanied the change in the eruptive style, providing information about the magmatic conduit involved in their seismogenetic processes. The effusive phase stopped on April 2, 2007, and the typical Strombolian activity restarted some months later.
\end{abstract}

Key words Stromboli - volcano monitoring - volcano seismicity

\section{Introduction}

When using seismology for monitoring a volcanic system characterized by a permanent eruptive state, the objective is to detect small but significant changes in the seismic activity. This requires high resolution analysis and pow-

Mailing address: Dr. Marcello Martini, Istituto Nazionale di Geofisica e Vulcanologia, Osservatorio Vesuviano, Sezione di Napoli, Via Diocleziano 328, 80124 Napoli, Italy; e-mail: martini@ov.ingv.it erful systems for automatic data processing. The case of Stromboli is an interesting application of these techniques.

Stromboli is a stratovolcano in the Mediterranean Sea that is characterized by an almost persistent explosive activity that arises at different vents in the summit area (Barberi et al., 1993; Bertagnini et al., 1999; Rosi et al., 2000; Calvari et al., 2005). This activity was documented in the first century by the Greek geographer Strabo. Occasionally, effusive activity occurred as well, usually producing lava flows on the «la Sciara del Fuoco» side (fig. 1). Sometimes, major explosions occurred as isolated episodes, with the ejection of juvenile magma and lithic bombs (Métrich et al., 2005).

In December 2002, the typical explosive activity was interrupted by an effusive phase, with 


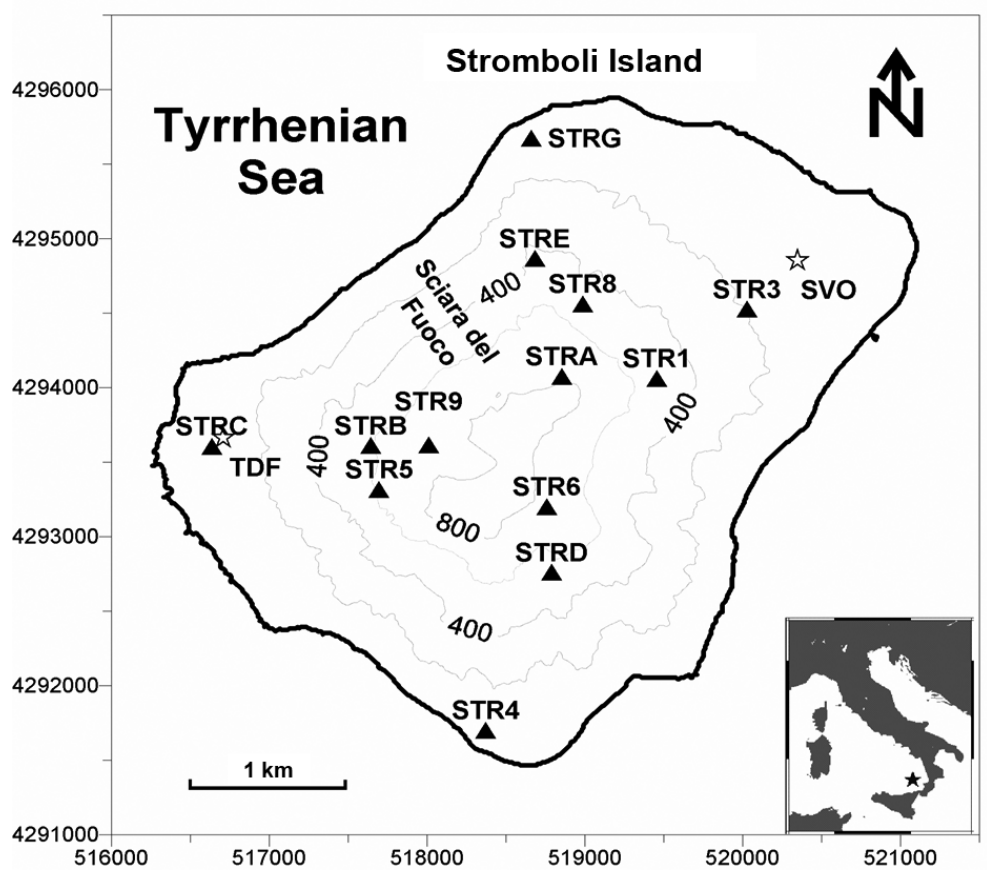

Fig. 1. Map of Stromboli volcano: the triangles indicate the 13 seismic stations of the permanent broadband network; the stars specify the locations of the two strainmeters (SVO and TDF). The inset shows a map of Italy with the position of Stromboli marked (star). The scale is expressed in UTC coordinates.

lava flowing from fractures that opened on the NW flank of the volcano at about $600 \mathrm{~m}$ a.s.l. This phase ended in July 2003. Tsunamigenic landslides accompanied the beginning of the effusive eruption and damaged the island coasts, causing alarm on the surrounding islands as well (Bonaccorso et al., 2003; Tinti et al., 2003; La Rocca et al., 2004). On that occasion, the Istituto Nazionale di Geofisica e Vulcanologia (INGV) deployed a broadband seismic network to monitor the volcanic emergency (fig. 1). At the same time, a cluster computing-based system was developed for automatically analyzing the data from the broadband network. This is integrated with web applications that allow remote access to the analysis results (http://eolo.ov.ingv.it). So far, this system has continuously produced very useful information about the state of the volcano in real time.

During the 2002-2003 crisis on April 5, a vulcanian explosion occurred (Calvari et al., 2005).
The signal recorded by the broadband seismic network allowed insight to be obtained into the explosion dynamics and indicated that a deformation of the volcanic edifice occurred before the explosion (D'Auria et al., 2006a). This episode encouraged the idea of installing strainmeters (Agustsson et al., 2000) to measure the elastic deformation detected by the broadband seismometers before the explosion, so using more appropriate instruments, in case of another explosion of the same size. In 2006, this idea was realized with the installation of two strainmeters on the opposite sides of the island (fig. 1).

Starting in 2006, a moderate, but unusual, volcano tectonic seismicity was recorded, with hypocenters located inside the volcanic structure (D'Auria et al., 2006b).

On February 27, 2007, the volcano started a new effusive phase. On March 15, 2007, a new violent vulcanian explosion occurred, with features similar to the one of April 5, 2003. On this 
occasion, the strainmeters recorded an interesting signal some minutes before the explosion.

In the following sections, we introduce the general features of the Stromboli seismicity and show how the monitoring system allowed the early identification of anomalies in the seismicity due to the incoming changes in the eruptive style. Then we describe the seismic and dilatometric data of the vulcanian explosion that occurred on March 15, 2007, highlighting the successful implementation of the strainmeters that recorded a strain increase before the explosion. Finally, we discuss our results and present our conclusions.
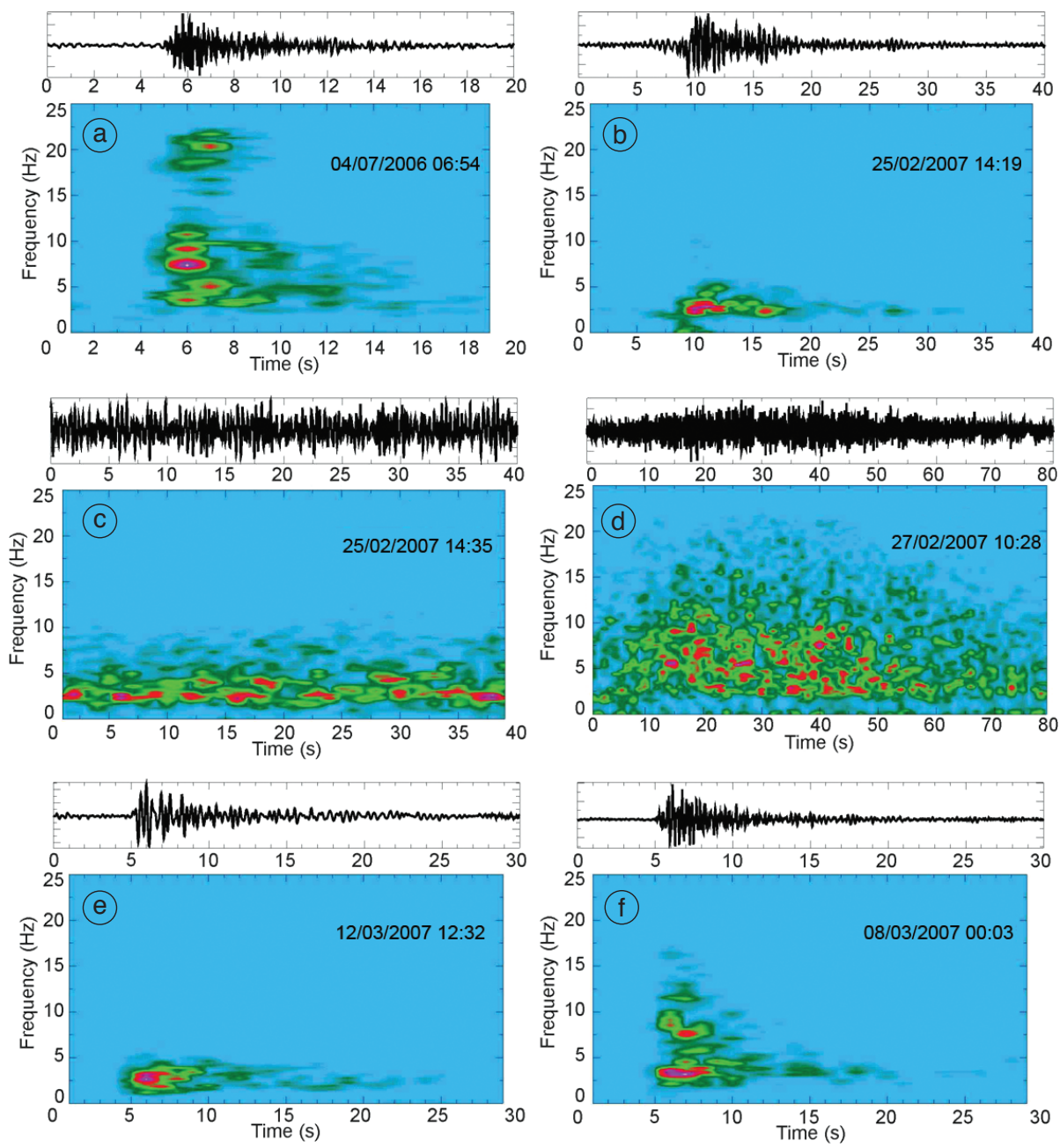

Fig. 2a-f. Seismograms and relative spectrograms of a VT earthquake (a), an explosion-quake (b) a volcanic tremor window (c), a landslide (d) a Long Period event during the effusive phase (e) and an hybrid event (f). Amplitudes are normalized for both seismograms and spectrograms. Note the similarity among (b) and (e). They are actually related to the same source mechanism (gas slug bursting) that during the effusive phase does not produce summit Strombolian explosions. 


\section{Stromboli seismicity}

The Strombolian activity is characterized by relatively low-level explosive eruptions that result in the ejection of variously sized incandescent magma fragments to altitudes of tens to hundreds of meters. Indeed, this type of activity is named after Stromboli, where is has continued for more than 1000 years.

In Stromboli, the explosions usually occur with a frequency that ranges from 5-6 to more then 20 events per hour. Each explosion generates a transient seismic signal, known as an explosion-quake, which lacks clear seismic phases. This is a signal characterized by typical frequency contents (fig. 2b). Usually it shows a component in the range of 1-6 Hz that is superimposed on a Very Long Period (VLP) component with a frequency in the range of 0.5-0.05 $\mathrm{Hz}$. These two components of the seismic radiation are linked to different source processes that are generated by the explosions, and they can be analyzed by different techniques. In particular, on the basis of the VLP source investigations, that have revealed a volumetric component in their mechanisms, these events are attributed to processes caused by the mass transport through the magma conduits (Chouet, 2003; Chouet et al., 2003). They are characterized by a rectilinear polarization towards the source centroid.

Another signal that characterizes the background of the Stromboli seismicity is the volcanic tremor, a continuous permanent signal for which the spectrum is very narrow-band (1-3 Hz) (fig. 2c) (Chouet, 1996). So the seismicity associated with the typical Strombolian activity is characterized by different source processes that generate radiation in different frequency bands. Figure 3 shows the February 16, 2007, daily spectrogram computed on a 15 -min sliding window (bottom panel) and the daily spectrum calculated by averaging the spectra of the 15-min windows (top panel). These plots repre-
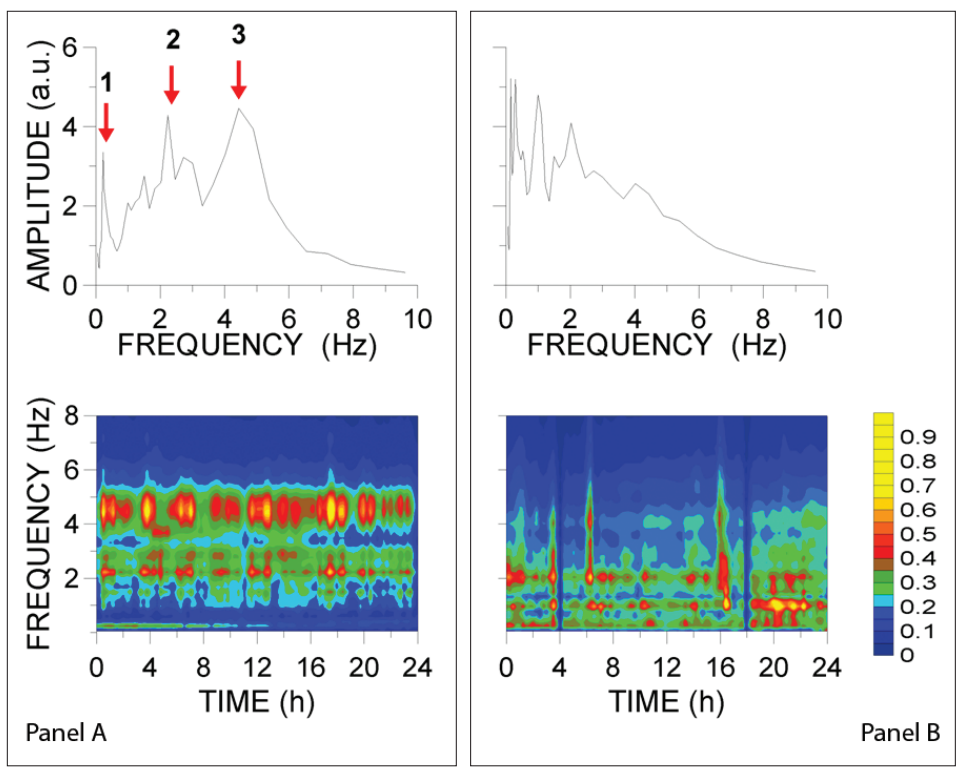

Fig. 3. Daily average spectra (top), expressed in arbitrary units (a.u.), and spectrograms (bottom) of seismic signals (STR1, vertical component) computed on a 15-min sliding window. Panel A shows the typical Strombolian activity (February 16, 2007). Spectral peak 1 corresponds to the VLP component; peak 2 is associated with the volcanic tremor; peak 3 represents the explosion-quakes. Panel B shows the seismic activity after the beginning of the effusive phase (February 28, 2007). Note that the distribution of the spectral amplitude changes; in particular, peak 3 is not distinguishable. 
sent the seismicity associated with the typical Strombolian activity and show the average characteristics of the wave-field frequency content. The continuous signal in the narrow band around $2 \mathrm{~Hz}$ is the volcanic tremor (fig. 2c). In correspondence with the explosions, three different frequency bands appeared (fig. 2b). The lower one $(0.5-0.05 \mathrm{~Hz})$ represents the VLP pulse associated with the explosion, the central (about $2 \mathrm{~Hz}$ ) is partially due to the background volcanic tremor, and the upper one $(2-6 \mathrm{~Hz})$ represents the higher frequency excited by the explosion (explosion-quake). The long-duration transient signals with spectral content in the rang 2-10 Hz are due to landslides (fig. 2d). The landslide signals have a variable occurrence, fluctuating around an average of 1-2 events per day. It has been demonstrated that these events can be successfully distinguished by using automatic classifiers based on neural networks (Esposito et al., 2006).

Over the last few years, low energy Volcano Tectonic (VT) events have also been recorded on Stromboli. Figure 2a shows the seismogram and the spectrogram of a VT earthquake recorded on December 11, 2006.

\section{The monitoring system}

The seismic network is composed of 13 digital stations that are equipped with Guralp CMG $40 \mathrm{~T}$ broadband sensors (fig. 1). The signal is sampled at $50 \mathrm{~Hz}$ by 24-bit GAIA type recorders, a digital recorder developed by INGV. To collect the data in real time, two different acquisition centers are used, one on Stromboli and the other on Lipari Island. The data are transmitted by radio link, encoded in packets of $2 \mathrm{~s}$, from the stations to one of the two recording centers on the basis of visibility between the station site and the location of the recording center. From the recording centers, the data are then transmitted to the Osservatorio Vesuviano (INGV) in Naples and INGV monitoring centers in Catania and Rome, using TCP/IP. In Naples, the data are automatically processed by the system known as EOLO (http://eolo.ov.ingv.it). This system continuously analyzes the incoming signals in order to detect and simultaneously locate the VLP events. The detection and the location of the VLP events are performed by using a technique based on Semblance analysis (Neidell and Taner, 1971). Eolo also performs other data analyses, including amplitude, spectra and polarization analyses. The polarization vector is obtained by calculating the eigenvalues and the eigenvectors of the covariance matrix of the 3-component filtered signals, following Montalbetti and Kanasewich (1970). To run the analysis processes in real time, this system uses a Linux cluster with 132 processors (D'Auria et al., 2004).

In 2006, two strainmeters were installed on Stromboli, the first at the Timpone del Fuoco site (TDF), close to the small village of Ginostra, and the second close to the local Civil Defense Centre (SVO) (fig. 1). The data acquisition is carried out using a 24-bit digital recorder. The data are centralized in Stromboli and then sent to Naples through the TCP/IP. The data acquired are the output of the volumetric transducers, the air pressure and the temperature.

All of these signals are sampled at $1 \mathrm{~Hz}$. In addition, the volumetric transducers are also sampled at $50 \mathrm{~Hz}$.

\section{The period preceding the effusive eruption}

The period before the effusive phase was characterized by a progressive increment of VLP occurrence rate (fig. 4) and by a moderate increment of the VLP amplitude (fig. 5), calculated as the maximum absolute value of the radial component with respect to the source location. The VLP occurrence started to increase at approximately the end of December 2006, and became less remarkable during the seven days before the effusive phase. In the same period, the VLP locations, did not show significant changes as calculated by radial semblance analysis (Chouet et al., 1999) and illustrate in fig. 6a-d. They were clustered in a small volume about $200 \mathrm{~m}$ beneath the summit craters, shifted towards the «La Sciara del Fuoco» border. Also, the azimuth and the inclination of the VLP polarization tensor were very stable over this period, confirming the stability of the source location (fig. 7). 

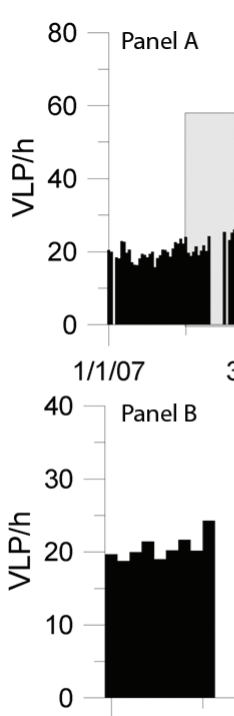

(4)
$2 / 1 / 07 \quad 3 / 07 \quad 3 / 3 / 07$
DATE $(\mathrm{m} / \mathrm{d} / \mathrm{yy})^{3}$
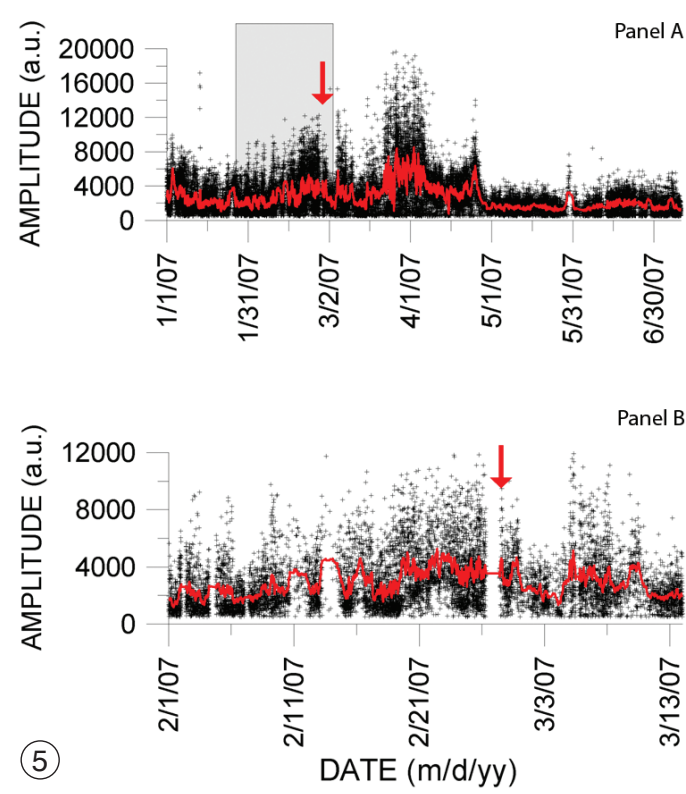

Fig. 4. VLP hourly frequency from January 1, 2007 to July 10, 2007 (panel A). The red arrow marks the onset of the effusive eruption. Panel B shows the VLP hourly frequency in the time window (February 1-March 14, 2007) marked by the gray rectangle in the panel A.

Fig. 5. VLP amplitude versus time (STR1) for the period from January 1, 2007 to July 10, 2007 (panel A). The solid red line shows the running average calculated on a 41-point window. The red arrow marks the onset of the effusive eruption. Panel B shows the VLP amplitude in the time window (February 1-March 14, 2007) marked by the gray rectangle in the panel $\mathrm{A}$.

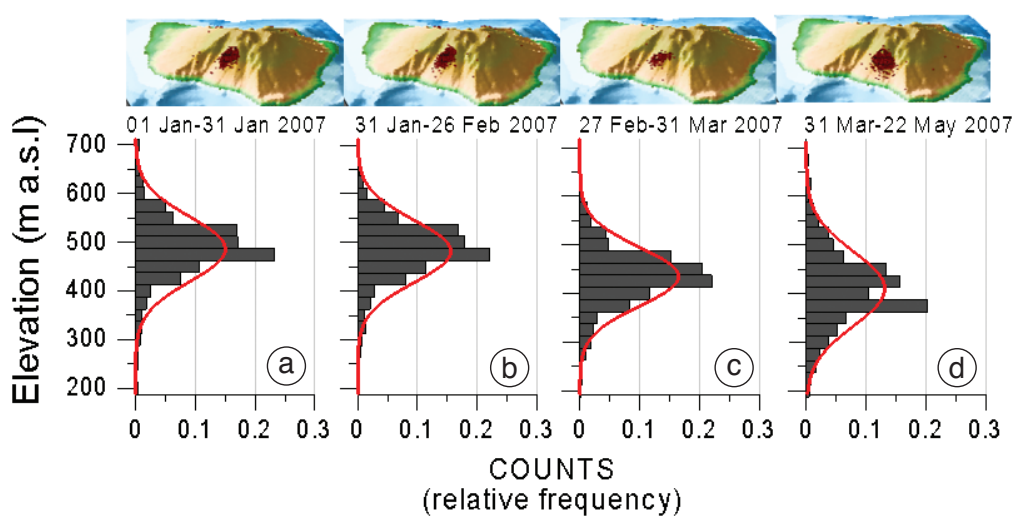

Fig. 6a-d. The VLP location and the histograms of the hypocentral elevation before and after the beginning of the effusive eruption (February 27, 2007). The elevation is expressed as meters above sea level. The temporal range is divided in four intervals: a) January 1-31; b) January 31-Februay 26; c) February 27-March 31; d) March 31-May 22. Note that there are no significant changes between the (a) and (b) periods (before the effusive phase), whereas a progressive elevation decrease is evident in (c) and (d) (after the beginning of the effusive phase). 


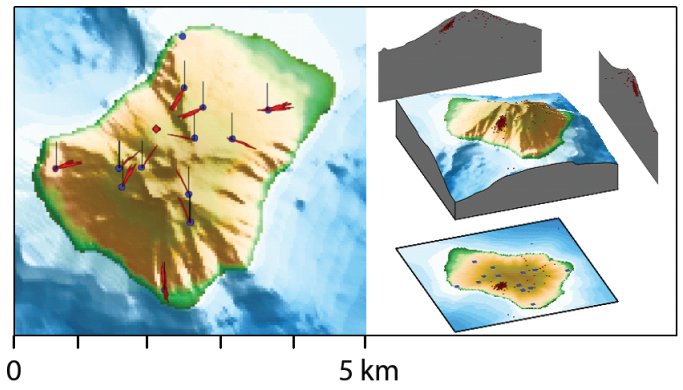

Fig. 7. Azimuth and inclination of the polarization vectors (left) and locations (right) of 1.338 VLP events recorded over the days before the onset of the effusive phase (February 24-27, 2007). The azimuth and inclination of the polarization vectors are represented by a rose diagram. The vertical bar points toward North. The versus of the azimuth expresses the dip direction of the principal polarization vector. Note that for same stations the dip is away from the source because the station has a lower elevation. In any case the polarization vector is mainly horizontal at all the stations.

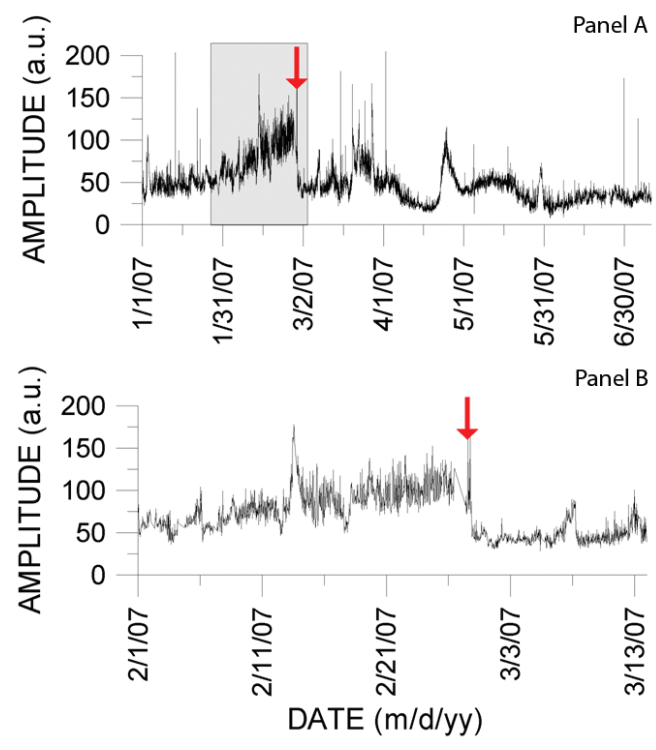

Fig. 8. The trend of the seismic amplitude (STR1, E$\mathrm{W}$ component) in the period from January 1,2007 , to July 10, 2007 (panel A). The red arrow marks the onset of the effusive eruption. Panel B shows the time window (February 1-March 14, 2007) marked by the gray rectangle in panel A. Before the effusive phase, an increment is evident from the end of January.
In the period from December 2006 to February 2007 , the volcanic tremor level, calculated as the average amplitude of the raw seismic signal over 15 -min windows, showed the trend illustrated in fig. 8. An increment is evident starting from the end of January, 2007.

Four hours before the beginning of the effusive phase, several landslide seismic signals appeared, sometimes forming a continuous signal superimposed on the volcanic tremor, as described in the following section.

\section{The effusive eruption onset}

On February 27, 2007, by about 09:00 UTC, a landslide signal was seen by the analysts involved in the surveillance activity. Signals of the same type continued for the next few hours. The occurrence of such signals was recognized as an anomaly and was communicated to the Civil Protection authorities.

At 12:34 UTC, as reported in the INGV surveillance bulletin on the basis of the images coming from a thermal camera (Cristaldi, 2007, on line at: http://www.ct.ingv.it/ Report/WKRVGALT20070301.pdf), the volcano started the effusive phase, and at 12:39 UTC a stronger landslide seismic signal was recorded. The lava flowed from a fracture that opened in the North-East crater, down the «La Sciara del Fuoco» flank. With the beginning of the lava flow, the explosive activity at the summit vents ceased. The amplitude of the VLP events temporarily increased and their waveforms changed significantly. The polarization properties of VLPs started changing, indicating a variation in their source location. In particular, the dip of the polarization vector increased by about $3-5^{\circ}$ indicating an increment in the VLP source depths. Figure 9a,b shows the rose diagram of the principal polarization vector dips of 594 VLP events recorded before the beginning of the effusive phase (A) and 341 events recorded immediately after the effusive phase started, at the STR6 station. The depth obtained by semblance analysis location clearly showed the same trend (fig. 6a-d).

In the first few hours of the effusive phase, the tremor amplitude showed two episodes of 


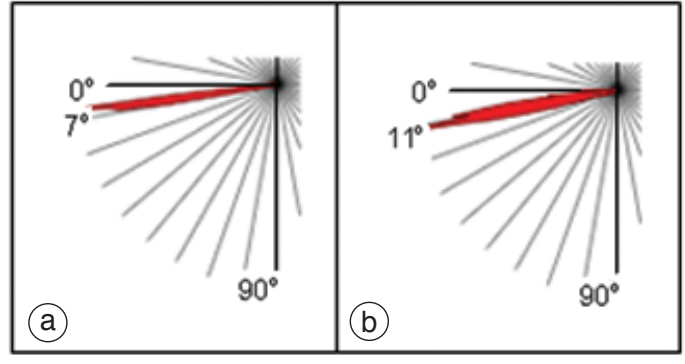

Fig. 9a,b. Inclination changes (expressed in degrees) of the polarization vector at the beginning of the effusive phase (STR6 station): a) the 24-h interval before the effusive phase (February 25, 2007, 00:00-February 26, 2007, 00:00; 594 VLPs); b) the 24-h interval after the beginning of the effusive phase (February 27, 2007, 12:00-February 28, 2007, 12:00; 341 VLPs). The inclination increased by $4^{\circ}$.

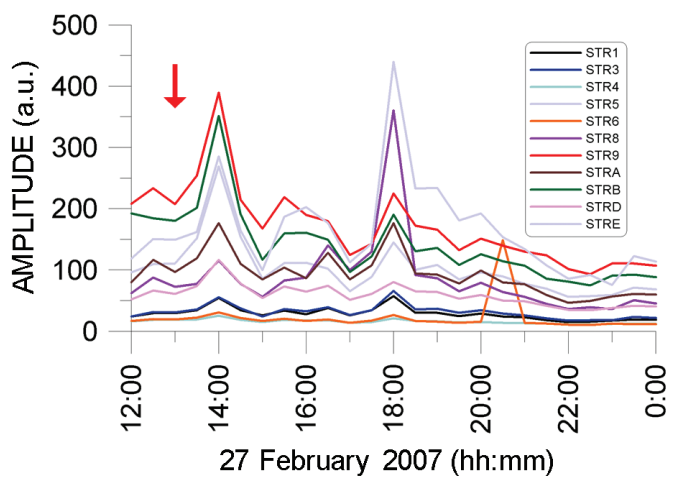

Fig. 10. The seismic amplitude in the hours following the beginning of the effusive phase (marked by the red arrow). Note the two episodes of volcanic tremor increments at about 14:00 and 18:00.

strong incrementation (fig. 10), and then it dropped down to a very low level (fig. 8).

These two episodes have distinctive spectral features that make them clearly distinguishable from the common volcanic tremor. One of the most interesting features is that the amplitude was maximum at the STR8 station (located close to the «Sciara del Fuoco») (fig. 1). For this reason, we believe that these tremor episodes were related to the subsequent opening of an eruptive vent on the «Sciara del Fuoco» at 18:30 UTC.
The seismicity accompanying the effusive phase shows features that are different from those of the typical Strombolian activity. Figure 3 shows the February 28, 2007, daily spectrogram computed for a 15 -min sliding window (bottom panel) and the relative daily spectrum (upper panel). Comparing fig. 3 (bottom panel) and fig. 3 (upper panel), we can see that after the beginning of the effusive phase, the relative distribution of the wave-field frequency content changed. By simply looking at the seismograms in fig. 11 , we can note that the volcanic tremor had a very low amplitude and that the higher frequency signals associated with the explosive activity in the crater zone were no longer detected.

\section{The evolution of the seismicity through March}

Through March, 2007, the waveform of VLP signals changed over time. Over the same period, their duration increased, suggesting a transition from an impulsive to a sustained mechanism in the volumetric components of the VLP source.

On March 15, 2007, at 20:37 UTC, a vulcanian explosion occurred with features similar to that of April 5, 2003 (D'Auria et al., 2006a). The strainmeters recorded the event and revealed a signal due to a strain increase starting about $10 \mathrm{~min}$ before the explosion (fig. 12). This evidence has provided a new perspective in the forecasting of the major explosions of Stromboli. About 2 min before the explosion, the broadband seismometers also recorded the onset of an Ultra Long Period (ULP) signal (fig. 13), with a seismic signature similar to that of April 5, 2003.

Many LP and hybrid events were recorded during the effusive phase. In particular, two main swarms of hybrid events were recorded on March 6-8 (fig. 14) and on March 20 (fig. 15). In the first, more then 2000 events were recorded. Some of these were located by using a probabilistic approach based on a grid search method. We manually picked the onset of the events and used a 3D $10 \mathrm{~m}$ spaced grid with a velocity model that assumes a constant velocity of $P$ waves of $3 \mathrm{~km} / \mathrm{s}$. 

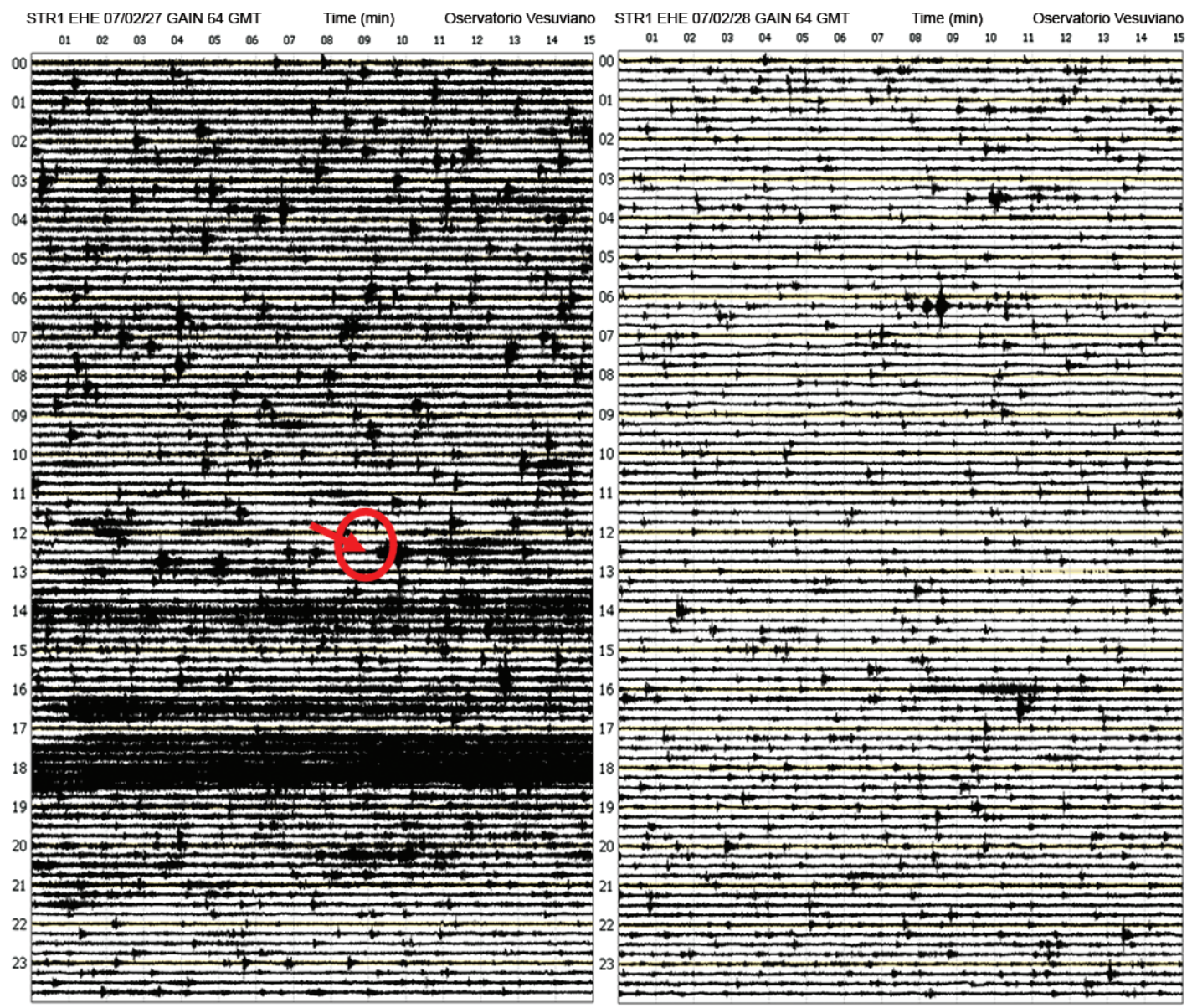

Fig. 11. The seismograms of February 27 and 28, 2007: the red circle indicates the start of the effusive eruption.

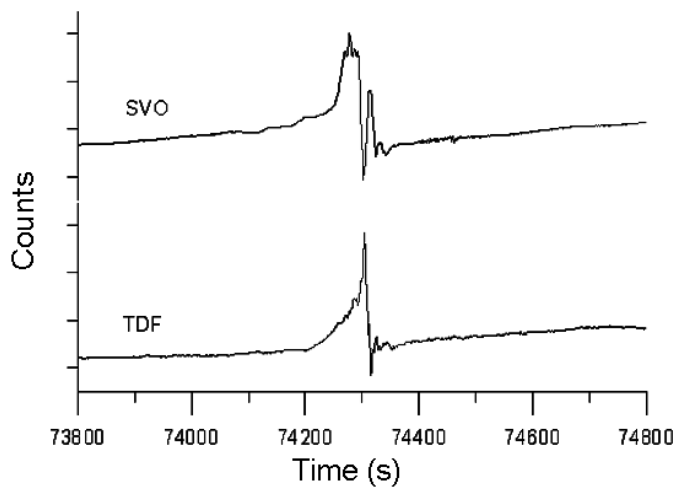

Fig. 12. The signal associated with the vulcanian explosion that occurred on March 15, 2007, at about 20:37 UTC, recorded by the two strainmeters: SVO (top) and TDF (bottom). The signal reveals a pressure increase starting about $10 \mathrm{~min}$ before the explosion.

The maximum likelihood hypocenters are reported in fig. 16. Due to the approximation to a constant velocity model, the location uncertainties can be large. The hypocenters result clustered in a small volume close to the summit craters of the 


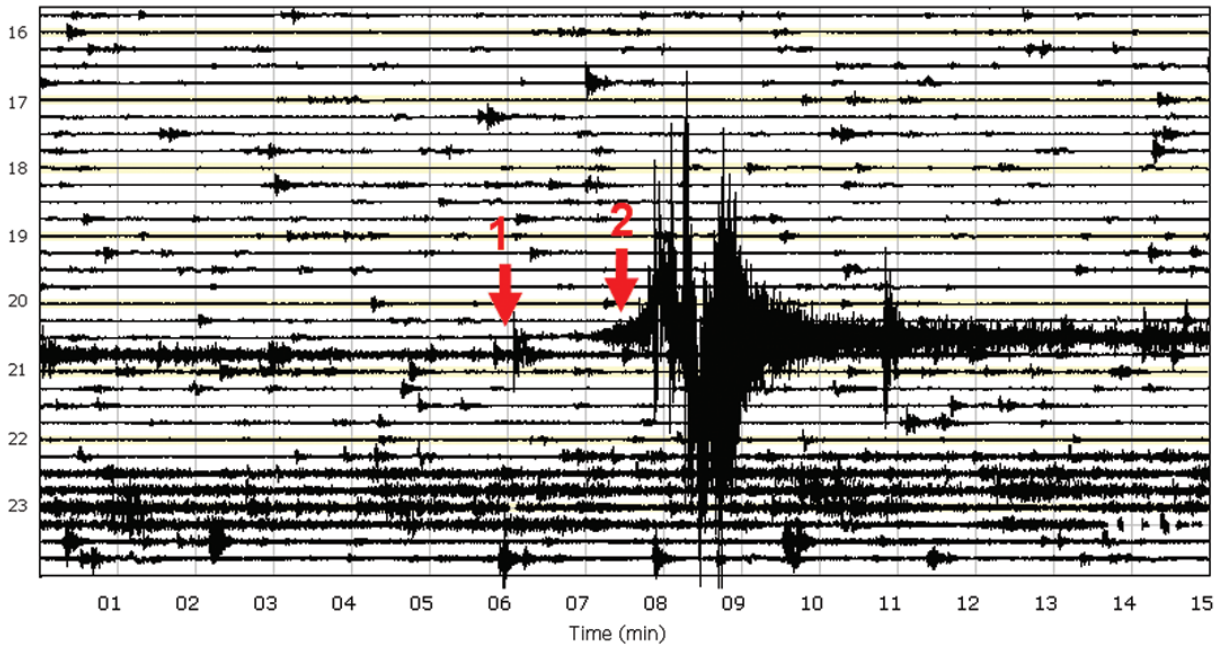

Fig. 13. The seismic signal of the March 15 explosion recorded by the STR 1 station (vertical component). Notice the Ultra Long Period (ULP) component (period of more than one minute). The moments of the beginning of the ULP signal (arrow 1) and the beginning of the explosion (arrow 2) are shown. The ULP onset is very gradual. The beginning time of the explosion is retrieved from infrared camera records.

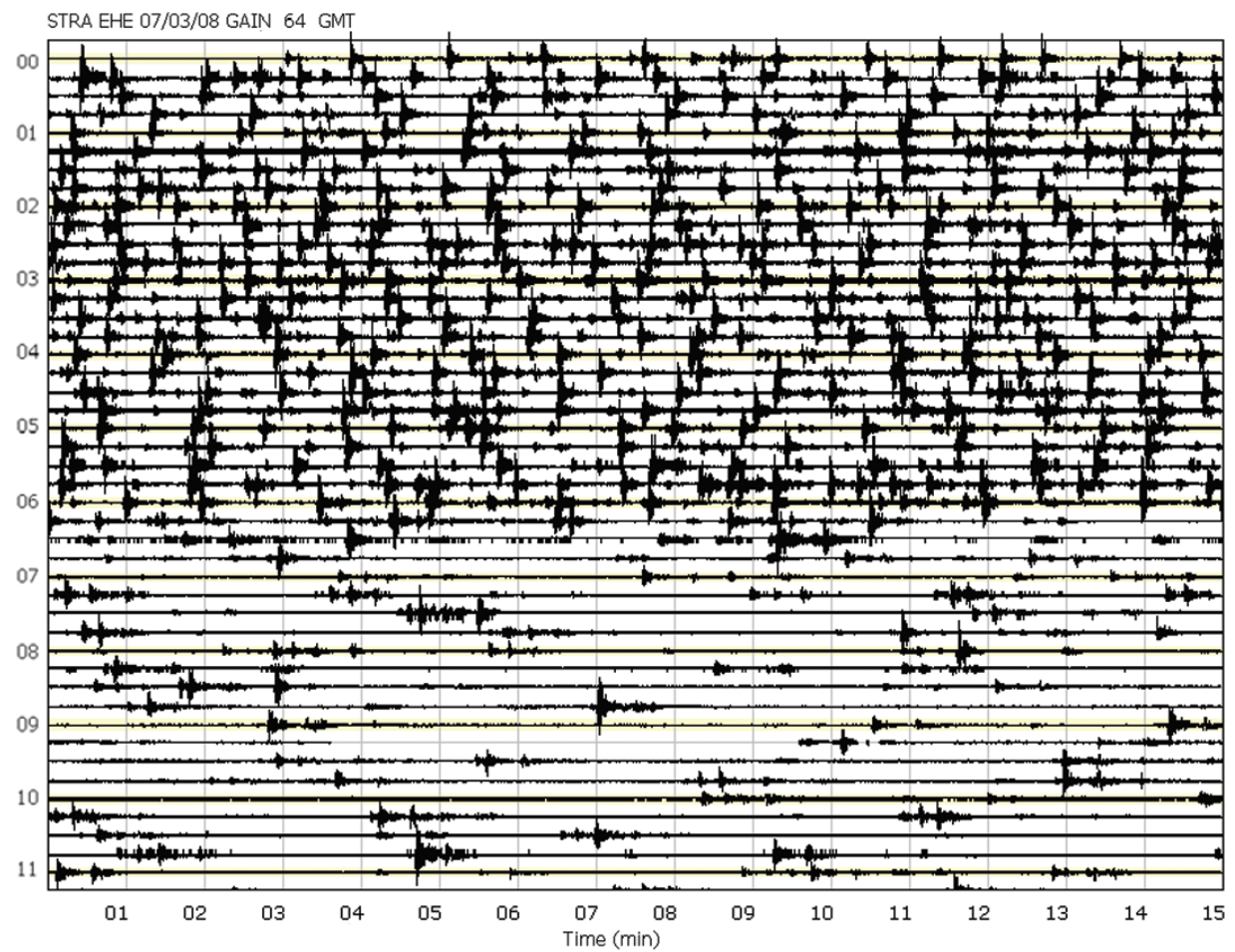

Fig. 14. The end of the swarm of more than 2000 hybrid events recorded during the March 6-8, 2007, period by the STRA station (east-west component). 


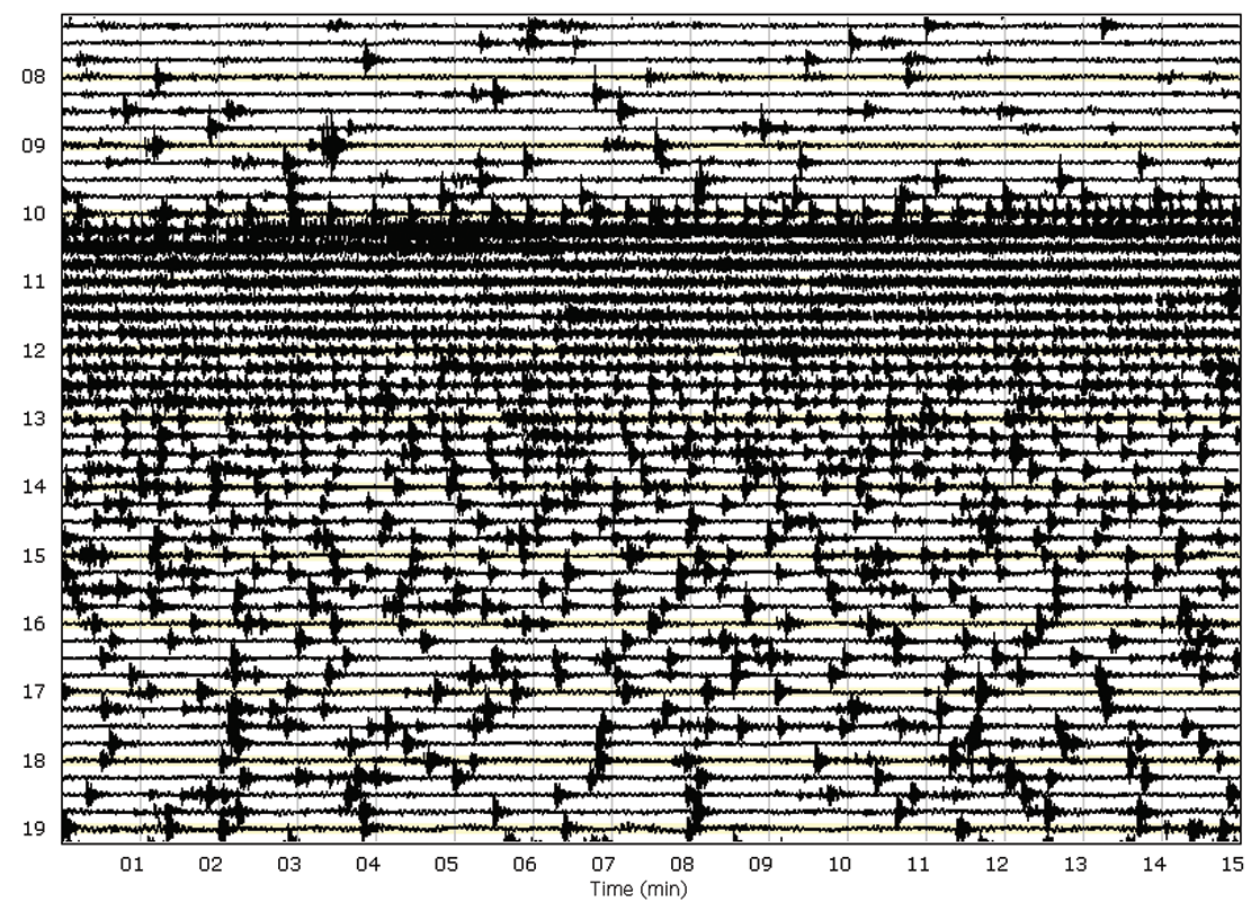

Fig. 15. The swarm of hybrid events recorded on March 20, 2007, by the STRA station (East-West component).

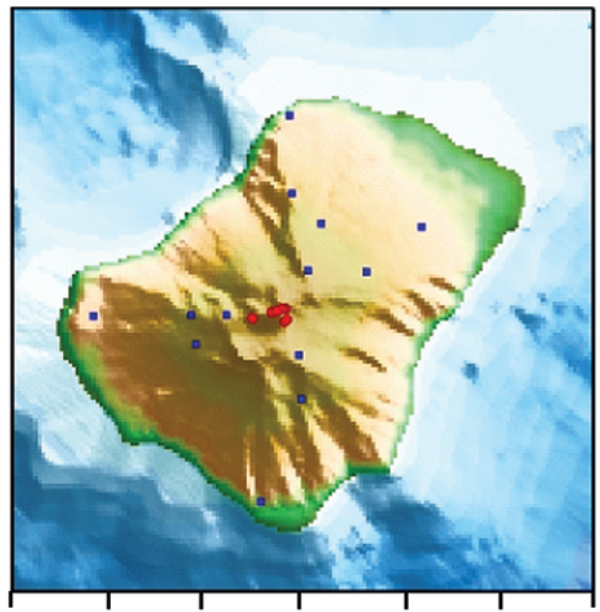

volcano. This episode was simultaneous with the collapse of the inner rim of the summit crater (Seismological Surveillance of Stromboli volcano, 2007).

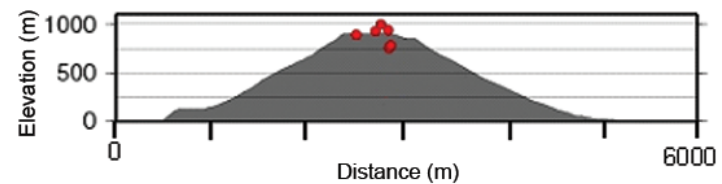

Fig. 16. Hypocenter locations of 5 hybrid events recorded on March 8, in the time range 00:00-00:30 UTC. The red points mark the maximum likelihood hypocenters, the blue squares indicate the seismic stations.

The second swarm started on March 20, at about 9:20 UTC, with an occurrence rate of one event every $2 \mathrm{~min}$. The occurrence rate rapidly increased while the amplitude decreased. This 
evolution resulted in the transition to a continuous tremor signal that lasted for about $2 \mathrm{~h}$ (fig. 15). By about 13:00 UTC, individual events started to emerge from the continuous signal, and the occurrence rate decreased. The swarm stopped during the night and included more than 1000 events.

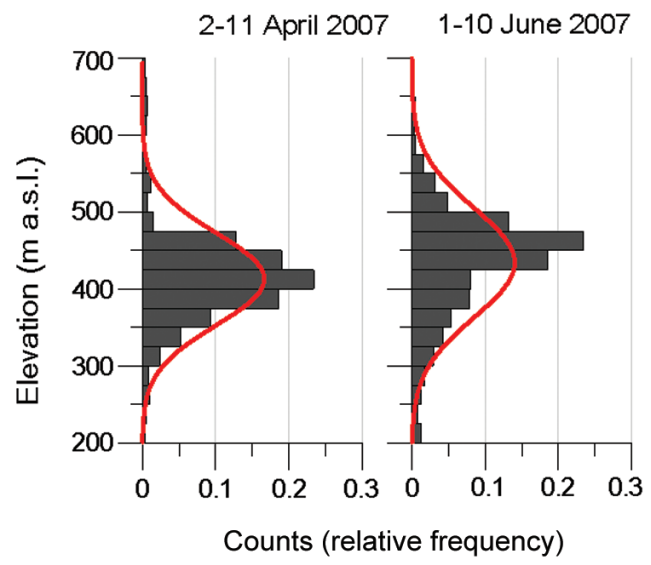

Fig. 17. Comparison of the depth distributions of the VLP hypocenters calculated by radial semblance analysis for two different periods after the end of the effusive eruption. Left: the period of April 2-11, 2007 (2711 VLP events). Right: the period of June 1-10, 2007 (2129 VLP events). Note the increase in the elevation over the periods considered.
The effusive phase ended on April 2, 2007. Immediately after the end of this phase, the seismicity did not show any significant changes. However, 25 days later, on April 21, an abrupt change occurred in the VLP amplitude and occurrence rate. In particular, the amplitude significantly decreased (fig. 5) and the occurrence rate increased, reaching peaks of more then 70 events/h (fig. 4). Together with these changes, a displacement of the source centroid toward the SW was observed.

Since the end of May 2007, the locations of the VLP sources have experienced new small changes and the heights of the hypocenters have moved slowly upwards (fig. 17).

\section{Discussion and conclusions}

The broadband seismic network installed on Stromboli and the cluster computing-based system that performs the data analysis in real time (http://eolo.ov.ingv.it), allowed the early recognition of changes in the seismicity, due to the incoming variations in the eruptive style on February 27, 2007. These systems also allowed the monitoring of the crisis evolution, giving us continuous information about the dynamics and the kinematic properties of the wave-field radiated by the volcano.

Comparing the last effusive episode with the 2002-2003 unrest, we can note some simi-

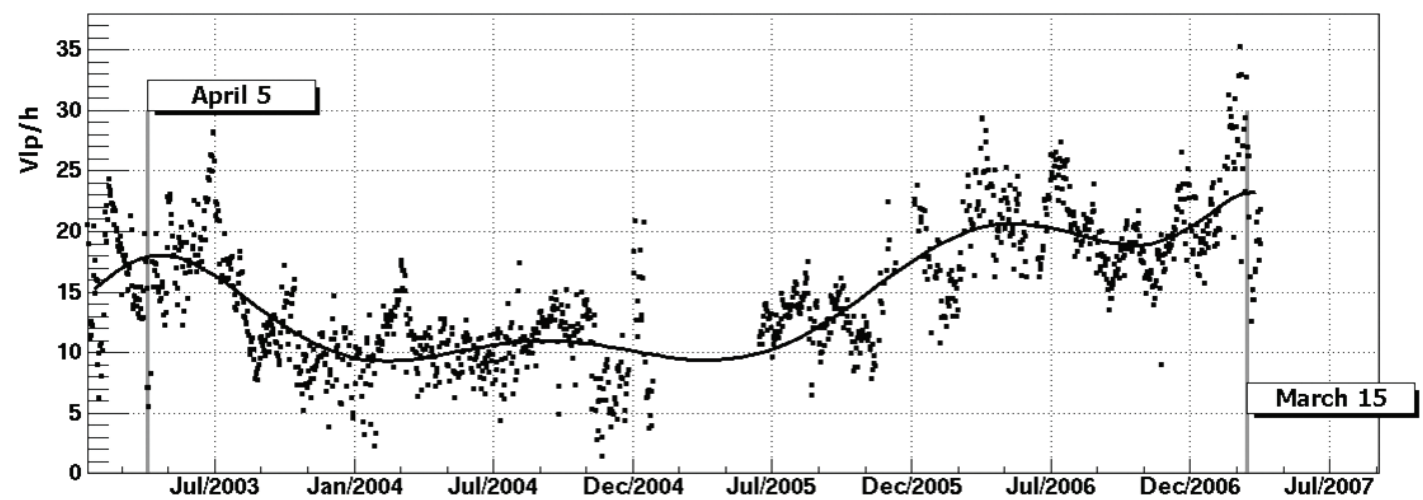

Fig. 18. VLP hourly occurrence rate since January 17, 2003. 
larities. The 2007 effusive phase began during a period characterized by a progressive increment of amplitude and occurrence rate of VLPs and by a gradual growth of the volcanic tremor amplitude. Also, the 2002-2003 effusive phase was preceded by a similar increase in the Strombolian activity, even if it was less documented.

The observations considered above suggest that in these two eruptive crises the transition to the effusive activity is primarily controlled by failure of the volcanic edifice under the effects due to the increased Strombolian activity. Actually the crater zone and the «Sciara del Fuoco» structures can be viewed as a system that is characterized by limited equilibrium conditions, so that a modest increase in the eruptive activity energy, evidenced by stronger and more frequent explosions, results in the transition to the effusive behavior through the failure of the shallow conduit walls. If we look at the historical records produced by the broadband network over the last 4 years, we find that the Strombolian activity has been characterized by moderate energy fluctuations during this period (fig. 18). The last of these was a little more intense than the previous ones, and generated the effusive phase. This thus means that it is reasonable to assume that while the volcano shows this activity style it is possible to estimate the probability of an effusive phase on the basis of the parameters observed.

For the short term precursors to the 2007 effusive phase, the most evident of these was the increase in the landslide occurrence a few hours before the beginning of the lava flow. On the basis of many direct observations, the signals recorded can be associated with the mobilization of unconsolidated pyroclastic material that lies on the «Sciara del Fuoco» flank at its repose angle. This suggests that the landslide increase was due to the incipient opening of an eruptive vent.

The strainmeters recorded very clear signals $10 \mathrm{~min}$ before the major explosion occurred during the effusive phase on March 15, 2007. These signals are the first records that are reasonably attributable to the physical process that preceded the major explosion at Stromboli volcano. So far, only very short term precursors have been measured for this type of event, start- ing about 2-3 min before a blast (D'Auria et al., 2006a).

After the onset of the effusive phase, interesting information about the evolution of the eruptive process was provided by the automatic locations of the VLP events and from the automatic polarization analysis performed in real time by EOLO (http://eolo.ov.ingv.it). More than 30700 events were automatically analyzed by the system during this period. The results revealed slight but consistent changes in VLP locations, which moved downwards during the effusive activity, and then in a South-West direction (from April 21, 2007). They then moved back to their previous locations after the end of the effusive process.

A large amount of high quality data was recorded during this unrest of the Stromboli volcano. Detailed analysis of the different aspects contained in these datasets will be the object of the future developments of this study.

\section{REFERENCES}

Agustsson, K., R. Stefansson, A.T. Linde, P. Einarsson, I.S. SACKS, G.B. Gudmundsson and B. ThorbuarnDOTTIR (2000): Successful prediction and warning of the 2000 eruption of Hekla based on seismicity and strain changes, Eos, Trans. Am. Geophys. Un., 81 (48), Fall Meet. Suppl., Abstract xxxxx-xx.

BARberi, F., M. Rosi and A. SoDI (1993): Volcanic hazard assessment at Stromboli based on review of historical data, Acta Vulcanol., 3, 173-187.

Bertagnini, A., M. Coltelli, P. Landi, M. Pompilio and M. Rosi (1999): Violent explosions yield new insights into dynamics of Stromboli volcano, Eos, Trans. Am. Geophys. Un., 80 (52), 633-636, doi: 10.1029/99EO00415..

Bonaccorso, A., S. Calvari, G. Garfì, L. Lodato and D. PATANNÈ (2003): Dynamics of the December 2002 flank failure and tsunami at Stromboli volcano inferred by volcanological and geophysical observations, Geophys. Res. Lett., 30 (18), I1941, doi: 10.1029/2003GL017702.

Calvari, S., L. Spampinato, L. Lodato, A.J.L. Harris, M.R. Patrick, J. Dehn, M.R. Burton and D. Andronico (2005): Chronology and complex volcanic processes during the 2002-2003 flank eruption at Stromboli volcano (Italy) reconstructed from direct observations and surveys with a handheld thermal camera, J. Geophys. Res., 110 (B02201), doi: 10.1029/2004JB003129.

Chouet, B. (1996): New methods and future trends in seismological volcano monitoring, in Monitoring and Mitigation of Volcano Hazard, edited by R. SCARPA and R.I. TILling (Springer), 23-97.

Chouet, B., (2003): Volcano seismology, Pure App. Geophys., 160 (3-4), doi: 10.1007/PL00012556, 739-788.

Chouet, B., G. Saccorotti, P. Dawson, M. Martini, R. 
Scarpa, G. De Luca, G. Milana and M. Cattaneo (1999): Broadband measurements of the sources of explosions at Stromboli Volcano, Italy, Geophys. Res. Lett., 26 (13),1999GL900400, pp. 1937.

Chouet, B., P. Dawson, T. Ohminato, M. Martini, G. SaCCOROTTI, F. Giudicepietro, G. De LuCA, G. Milana and R. SCARPA (2003): Source mechanisms of explosions at Stromboli Volcano, Italy, determined from moment-tensor inversions of very-long-period data, J. Geophys. Res., 108 (B1), 2019-2044, doi: 10.129/ 2002JB001919.

CRISTAldi, A. (2007): Rapporto Settimanale sull'Attività Eruttiva dello Stromboli, February 19-27, 2007 (available on line at: http://www.ct.ingv.it/Report/WKRVGALT20070301.pdf).

D'Auria, L., M. Martini, E. Auger, F. Giudicepietro, W. DE Cesare and G. Scarpato (2004): Real-time automatic seismic monitoring of Stromboli using massive parallel computing, in IAVCEI General Assembly, November 2004, Pucon, Chile.

D'Auria, L., F. Giudicepietro, M. Martini and R. Peluso (2006a): Seismological insight into the kinematics of the 5 April 2003 vulcanian explosion at Stromboli volcano (Southern Italy), Geophys. Res. Lett., 33, L08308, doi: 10.1029/2006GL026018.

D'Auria, L., F. Giudicepietro, M. Martini and M. OraZi (2006b): The April-May 2006 Volcano-Tectonic Events at Stromboli Volcano (Southern Italy) and their Relation with the Magmatic System (available on line at: http://hdl.handle.net/2122/1506).

Esposito, A.M., F. Giudicepietro, S. Scarpetta, L. D'AuRiA, M. Marinaro and M. Martini (2006): Automatic discrimination among landslide, explosion-quake and tremor seismic signals at Stromboli volcano using Neur- al Networks, Bull. Seismol. Soc. Am., 96 (4A), doi: 10.1785/0120050097, 1230-1240.

la Rocca, M., D. Galluzzo, G. Saccorotti, S. Tinti, G.B. Cimini and E. Del Pezzo (2004): Seismic signals associated with landslides and with a tsunami at Stromboli Volcano, Italy, Bull. Seismol. Soc. Am., 94 (5), 1850-1867.

Métrich, N., A. Bertagnini, P. Landi, M. Rosi and O. BeLHADJ (2005): Triggering mechanism at the origin of paroxysms at Stromboli (Aeolian Archipelago, Italy): the 5 April 2003 eruption, Geophys. Res. Lett., 32, L10305, doi:10.1029/2004GL022257.

Montalbetti, J.R. and E.R. KANASEWICH (1970): Enhancement of teleseismic body phases with a polarization filter, Geophys. J.R. Astron. Soc., 21, 119-129.

Neidell, N.S. and M. Turhan Taner (1971), Semblance and other coherency measures for multichannel data, Geophysics, 36 (3), 482-497 (June 1971).

Rosi, M., A. Bertagnini and P. LANDi (2000): Onset of the persistent activity at Stromboli Volcano (Italy), Bull. Volcanol., 62 (4-5), 294-300.

Seismological Surveillance of Stromboli volcano (2007): Daily Bulletin of the INGV - 03/08/2007 (available on line at: http://www.ct.ingv.it/Report/comunicato $\% 20 I N G V \% 2008 \% 20$ marzo\%202007.pdf).

Tinti, S., G. Pagnoni, F. Zaniboni and E. Bortolucci (2003): Tsunami generation in Stromboli Island and impact on the south-east Tyrrhenian coasts, Nat. Hazards Earth Sys. Sci., 3, 299-309.

(received August 22, 2007; accepted January 8, 2008) 